\title{
Sex and relationship dysfunction in neurological disability
}

\author{
B J Chandler, S Brown
}

\begin{abstract}
Objectives-(1) to ascertain how many people with neurological disability experience sexual or relationship problems; (2) to examine the interplay of neurological disability and sexual function within the context of the dyadic relationship; (3) to consider the implications of the results for service provision.

Methods-A survey of outpatients attending Hunters Moor Regional Rehabilitation Centre, Newcastle upon Tyne over a 6 month period. Standardised measures of sexual function and concern, relationship satisfaction, disability, and mental health were used.

Results-Seventy people were interviewed (18\% of the potential study population). Prevalence figures therefore refer to this self selected sample. Fifty one per cent had experienced a change in sexual function and $27 \%$ were concerned about this change. Of those in cohabiting relationships $25 \%$ were experiencing difficulties. Gender was significantly associated with concern about sexual function, men being more concerned. A high score on the marital adjustment scale indicating relationship dissatisfaction was the best predictor of change in and concern about sexual function. Change in sexual function and duration of illness were the most powerful predictors of relationship dissatisfaction.
\end{abstract}

Conclusion-If concern is taken as an indication of a desire for help more than one in four of this sample required help for sexual dysfunction. Sexual and relationship functioning were very closely associated and dysfunction in either of these areas was the best predictor of dysfunction in the other area. The dyadic relationship is an important institution in the management of disability. Sexual dysfunction can be predictive of difficulties within a relationship. Any service designed to address sexual health should also address relationship issues. (f Neurol Neurosurg Psychiatry 1998;65:877-880)

Keywords: sexual dysfunction; relationship satisfaction; neurological disability

Correspondence to: Dr B J Chandler, Hunters Moor Regional

Rehabilitation Centre, Hunters Road, Newcastle upon Tyne, NE2 4NR, UK

Received 29 January 1998 and in revised form 14 May 1998

Accepted 20 May 1998

Sexuality is one of the most complex aspects of human life. Sexual expression is dependent on functioning anatomical and physiological systems, which are influenced by cognitive and emotional processes. Other than in masturbation and fantasy, sexual expression occurs within the context of a dyadic relationship. To assess and treat problems in this area knowledge of those factors influencing both the dynamics of the relationship and the physical and psychological aspects of sexual functioning is necessary.

Neurological disease and trauma have long been recognised as causing sexual dysfunction. Detailed studies of sexual functioning among various diagnostic groups with neurological disability have disclosed a high prevalence of sexual dysfunction. ${ }^{1-12}$ For example, in multiple sclerosis over two thirds of men may have an unsatisfactory or inactive sex life, after traumatic brain injury $50 \%$ of men may experience sexual dysfunction, and in Parkinson's disease $50 \%$ of men and women may have sexual problems. ${ }^{13-15}$ However, the incidence of problems presented in routine consultations remains low. Szasz et al in a study of people with multiple sclerosis distinguished clearly between the presence of dysfunction and concern about the change. ${ }^{16}$ Although this research identified about half the study group as sexually less active or abstinent only $27 \%$ of the total group were concerned about the change. It was proposed that the concerned group represented those who would wish for treatment.

The intensely personal and private nature of sex produces a reticence on the part of patients in presenting sexual problems and in screening for such problems on the part of healthcare professionals. ${ }^{17-20}$ The associated lack of training in sexual medicine has not helped in developing services for this group of patients. ${ }^{21} 22$

This study examined sexual dysfunction within the context of the dyadic relationship and assessed the following issues.

- The prevalence of sexual or relationship problems among a population with neurological disability

- The interplay of neurological disability and sexual function within the context of the dyadic relationship

- The implications for service provision of sexual dysfunction of whatever cause or character in terms of the concern which participants in the study experienced in relation to their sex lives.

\section{Method}

STUDY POPULATION

Over a 6 month period all patients aged 16 to 64 years attending Hunters Moor Regional
Rehabilitation Centre (RRC) as outpatients were invited by letter to take part in the study. Hunters Moor RRC, based in Newcastle upon Tyne, offers rehabilitation to patients in the 16 to 64 age group who have experienced neurological disease or trauma. 
STUDY PLAN

The project was conducted in two phases. Phase 1 (reported in this paper) was an interview based survey with neurologically disabled subjects. Interviews were conducted by a research psychologist (SB) at the RRC unless the subject had indicated a wish to be interviewed at home. Phase 2 encompassed in depth focused interviews with a few subjects and their partners The interviews were recorded, transcribed, and coded for analysis (reported separately).

Having gathered general demographic information, specific measures were used.

MODIFIED MINI MENTAL STATE EXAMINATION

The modified mini mental state examination was used as a brief screen for severe impairment of cognitive functioning which would preclude a person from understanding the study questions. ${ }^{23}$ Those scoring less than 3 were excluded from the study. Less severe cognitive problems were accepted as part of the range of neurological disability and were identified on the subscale of the OPCS disability screening questionnaire.

\section{GENERAL HEALTH QUESTIONNAIRE 12 ITEM} VERSION ${ }^{24}$

Psychological distress is well recognised as a contributory factor in sexual or relationship dissatisfaction. ${ }^{25-26}$ The GHQ 12 provided a brief well validated screening tool for detecting general psychiatric morbidity. A score of 2 or more distinguished between psychologically distressed and non-distressed cases

OPCS DISABILITY SCALE

The OPCS disability scale gave an overall disability score as well as subscale scores for specific areas of disability. ${ }^{27}$ It has been validated in population based studies and has more recently been used as an alternative to the Kurtzke scale in a study of people with multiple sclerosis. ${ }^{28}$

GOLOMBOK RUST INVENTORY OF MARITAL STATE The Golombok Rust Inventory of marital state gave an overall score of relationship satisfaction. ${ }^{29}$ It was designed and validated for use among heterosexual people in cohabiting relationships. ${ }^{30}{ }^{31}$ The questionnaire comprises 28 items covering shared interests, independence, communication, decision making, warmth and love, trust and respect, role expectation and goals, commitment, extent of agreement, and attitudes to relationships.

SEXUAL FUNCTION SCALE ${ }^{16}$

The sexual function scale was originally designed for use in a population with multiple sclerosis. It consists of five points indicating a change in sexual function or concern about that change. It provides a subjective assessment of sexual satisfaction, which is arguably the most meaningful measure of sexual expression. A sixth category was used in this study to incorporate those subjects who were not in a current sexual relationship and therefore were not aware of altered sexual functioning.
SUBJECTS

The total number of potential respondents was 398 , of whom $44 \%$ were male and $56 \%$ were female, with a mean age of 46 years. Ninety two people agreed to take part in the study. Twenty two subjects were subsequently excluded; three because of cognitive problems and 19 who lived too far from the RRC to allow a home visit, which was their preference for the interview.

\section{Results}

DEMOGRAPHIC DETAILS

Seventy people were interviewed $(18 \%$ of the potential study population), 31 were men and 39 were women, with a mean age of 47 (SD 10) years. This was not significantly different from the age and sex distribution of the study population. The diagnoses included multiple sclerosis $(33 \%)$, focal dystonia (33\%), stroke $(14 \%)$, head injury $(6 \%)$, and various other conditions including generalised dystonia and spinal injury (14\%). Most of the sample was mild to moderately disabled with a mean score of 3.5 on the OPCS scale. Twenty subjects scored zero (no disability) and three scored 10 (very severely disabled). Forty two people scored two or more on the GHQ, implying psychiatric morbidity.

\section{RELATIONSHIPS}

Sixty seven per cent $(n=48)$ of the sample were married or cohabiting. Of those living alone $10 \%(n=7)$ had a stable relationship.

Of those in cohabiting relationships 30 subjects scored in the above average range of the GRIMS suggesting a high level of satisfaction with their relationship. Six had an average score. Seven scored in the range "poor" or "bad" and five had scores indicating severe relationship problems. In total $25 \%$ of those in a cohabiting relationship had problems of a sufficient magnitude to cause concern.

The influence of gender and diagnosis on relationship satisfaction was examined using a Mann-Whitney $U$ test. There was no significant difference in relationship satisfaction between men and women $(p=0.37)$. Examination of the two principal diagnostic groups showed that subjects with a diagnosis of multiple sclerosis or dystonia did not differ significantly in relationship satisfaction from other diagnostic groups $(p=0.28$ and 0.52 respectively).

A significant correlation between higher GRIMS scores (indicating poor relationship satisfaction) and increasing severity of disability was found (Spearman's $r=0.29, \mathrm{p}<0.05$ ). Duration of illness did not significantly influence relationship satisfaction (Spearman's $r$ test, $\mathrm{p}=0.29$ ).

There was no significant difference in relationship satisfaction between those who were and were not psychologically distressed as measured by the GHQ ( $\chi^{2}$ squared $\left.\mathrm{p}=0.48\right)$.

SEXUAL FUNCTIONING

Fifty one per cent $(n=36)$ of the sample had experienced a change in sexual function, sexual activity, or had become abstemious. Of these 
Table 1 Results using the Szasz sexual functioning scale

\begin{tabular}{lll}
\hline Raw scores & Interpretation & Frequency \\
\hline 0 & No change in sexual function & 28 \\
1 & Sexually less active/some sexual changes/not concerned & 7 \\
2 & Sexually less active/ some changes/concerned & $\mathbf{1 2}$ \\
3 & Sexually inactive (abstinent) concerned & 7 \\
4 & Sexually inactive (abstinent) not concerned & 10 \\
5 & Not in a sexual relationship/not aware of change & 6
\end{tabular}

people, over half $(n=19)$ expressed concern about this change (table 1). Those who were concerned showed significantly less psychological distress (assessed by the GHQ) than those not concerned (Fisher's exact test $\mathrm{p}=0.04)$. Change in sexual function alone did not correlate with psychological distress.

Gender was not significantly associated with change in sexual functioning but was associated with concern about sexual function (contingency coefficient $=0.28, \mathrm{p}<0.01$ ), with men being more concerned than women.

The overall disability score was not significantly associated with either change in sexual activity or concern about that change, but there were associations between particular subgroups on the scale assessed by the MannWhitney $U$ test.

Change in sexual functioning was significantly associated with difficulties in the areas of personal care $(p<0.02)$, locomotion $(p<0.02)$, and continence $(\mathrm{p}<0.01)$.

Concern about sexual function was associated with continence $(p<0.01)$.

Abstinence from sexual activity was significantly associated with the overall severity of disability $(p<0.01)$, and in particular with the subscale scores for personal care $(p<0.02)$, locomotion $(p<0.01)$, and intellectual function $(\mathrm{p}<0.01)$. Those with greater difficulties in these three areas were more likely to have become abstinent.

The influence of diagnosis on change in sexual function, concern, and abstinence was explored. A significant association between a diagnosis of multiple sclerosis, change in sexual function (contingency coefficient $=0.30$, $\mathrm{p}<0.01$ ), and abstinence (contingency coefficient $=0.36, \mathrm{p}<0.01$ ) was found but not between this diagnosis and concern.

SEXUAL AND RELATIONSHIP FUNCTION

Of the 48 people in cohabiting relationships 21 had not experienced a change in sexual function or activity and did not have any major relationship problems. Only one person experienced relationship difficulties in the absence of any sexual disturbance. The distribution of results for relationship and sexual functioning is shown in table 2 .

Table 2 Distribution of cases by sexual function and relationship satisfaction

\begin{tabular}{lll}
\hline & $\begin{array}{l}\text { No relationship } \\
\text { problems } \\
\text { GRIMS }<34\end{array}$ & $\begin{array}{l}\text { Relationship } \\
\text { problems } \\
\text { GRIMS } \geqslant 34\end{array}$ \\
\hline $\begin{array}{l}\text { No change in sexual function/activity or not aware of any change } \\
\begin{array}{l}\text { Some change in sexual function and/or activity or given up sex } \\
\text { and concerned about the change }\end{array}\end{array}$ & 21 & 1 \\
$\begin{array}{l}\text { Some change in sexual function and/or activity or given up sex } \\
\text { and not concerned about the change }\end{array}$ & 8 & 3 \\
\hline
\end{tabular}

Sexual function and relationship satisfaction were explored for association using a MannWhitney $U$ test. Scores on the GRIMS scale of marital satisfaction were significantly associated with change in sexual function $(p<0.01)$, concern about the change $(p<0.01)$, and abstinence $(p<0.01)$. People who were less satisfied with their relationship were more likely to have experienced altered sexual functioning and concern about this.

\section{PREDICTING CHANGE IN AND CONCERN ABOUT} SEXUAL FUNCTION

To assess which subjects were likely to experience change in and concern about sexual function, a series of logistic regression analyses were conducted.

The level of relationship satisfaction as measured by the GRIMS score was the greatest predictor of a change in and concern about sexual function and this accounted for $10 \%$ and $9 \%$ of the variance respectively. The greater the degree of distress between the partners, the greater the likelihood of a change in sexual function and concern about that change. Gender accounted for $6 \%$ of the variance in predicting concern about sexual function with men being more concerned than women. Relationship dysfunction was also the greatest predictor of sexual abstinence, accounting for $6 \%$ of the variance. The severity of disability accounted for $5 \%$ of the variance.

Overall a high GRIMS score ( $\geqslant 34$, indicating relationship problems) was the best predictor of sexual change, concern about that change, and abstinence.

\section{PREDICTING RELATIONSHIP DISSATISFACTION}

The predictors of relationship satisfaction were examined using a linear regression analysis. Change in sexual function and duration of illness were the most powerful predictors of relationship dissatisfaction, accounting for $21 \%$ and $7 \%$ of the variance respectively.

\section{Discussion}

This study provides descriptive data about sexual and relationship functioning among a self selected sample with neurological disability. Due to the low response rate reliable prevalence data cannot be derived.

Sexual and relationship dysfunction are not life threatening consequences of neurological disease, but their occurrence may be associated with a considerable amount of unhappiness and poor quality of life. ${ }^{32-35}$ Of those subjects who were aware of a change in sexual functioning over half were concerned about the change. This represented $27 \%$ of the study sample and supports the results of Szasz et al. ${ }^{16}$ In addition, $25 \%$ of couples were experiencing relationship problems sufficient to warrant intervention. This offers an indication of the proportion of people who might wish to access services dealing with sexual and relationship issues in the context disability.

For relationship satisfaction the greatest predictive factor of dysfunction was change in sexual functioning with duration of illness also contributing. The cause of sexual dysfunction 
is often multifactorial in origin incorporating an interplay of psychosocial and physical factors. ${ }^{36}$ Assessment and treatment of those factors, which are accessible, should provide a better therapeutic outcome and this is certainly an area to be further researched. Offering an assessment by a couple's therapist to those seeking help with sexual problems is a possible model and this has been successfully applied in a multidisciplinary diabetic clinic. ${ }^{37}$ There is evidence that combining marital therapy with psychosexual therapy results in a better outcome than either therapy alone. ${ }^{38}$

This study has demonstrated the close association between sexual and relationship dysfunction among people with neurological disability. Further research is needed to explore the most effective means of treating these common problems.

We are very grateful to Northern and Yorkshire Regional Health Authority for funding this study.

1 Hulter BM, Lundberg PO. Sexual function in women with advanced multiple sclerosis. F Neurol Neurosurg Psychiatry 1995;59:83-6.

2 Vas CJ. Sexual impotence and some autonomic disturbance in men with multiple sclerosis. Acta Neurol Scand 1969;45: in men 83 .

3 Valleroy ML, Kraft GH. Sexual dysfunction in multiple sclerosis. Arch Phys Med Rehabil 1984;65:125-8.

4 Garden FH. Incidence of sexual dysfunction in neurologic Garden FH. Incidence of sexual dysfunction in
disability. Sexuality and Disability 1991;9:39-47.

5 Elliott ML, Biever LS. Head injury and sexual dysfunction. Brain Inj 1996;10:703-17.

6 Clark JDA, Raggatt PR, Edwards OM. Hypothalamic hypogonadism following major head injury. Clin Endocrino 1988;29:153-65.

7 Sandel ME, Williams KS, Dellapietra L, et al. Sexual functioning following traumatic brain injury. Brain Inj 1996;10: 719-28.

8 Wermuth L, Stenager E. Sexual problems in young patients with Parkinsons disease. Acta Neurol Scand 1995;91:453-5.

9 Quinn NP, Toone AE, Marsden CD, et al. Dopa dose dependent sexual deviation. Br F Psychiatry 1983;142:296-$$
8 .
$$

10 Harvey NS. Serial cognitive profiles in levodopa induced hypersexuality. Br f Psychiatry 1988; 153:833-6.

11 Goodwin FK. Behavioural effeccts of L-dopa in man. Seminars in Psychiatry 1971;3:477-91.

12 Weinman E, Ruskin PE. Levodopa dependence and hypersexuality in an older Parkinsons disease patient. American fournal of Geriatric Psychiatry 1994;3:81-3.

13 Lilius HG, Valtonen EJ, Wikstrom J. Sexual problems in patients suffering from multiple sclerosis. f Chron Dis 1976;29:643-7.

14 O'Carroll RE, Woodrow J, Marouns F. Psychosexual and psychosocial sequelae of closed head injury. Brain Injury 1991;5:303-13.
15 Brown RG, Jahanshahi M, Quinn N, et al. Sexual function in patients with Parkinson's disease and their partners. $f \mathrm{Neu}$ rol Neurosurg Psychiatry 1990;53:480-6.

16 Szasz G, Paty D, Lawton-Speert S, et al. A sexual function scale in multiple sclerosis. Acta Neurol Scand 1984;101:37-

17 Finger WW, Hall ES, Peterson FL. Education in sexuality for nurses. Sexuality and Disability 1992;10:81-9.

18 Young EW. Patients' plea: tell us about our sexuality. fournal of Sex Education and Therapy 1984;10:53-6.

19 Weston A. Challenging assumptions. Nursing Times 1993; 89:26-31.

20 Sawyer SM. Reproductive and sexual health in adolescents with cystic fibrosis. BMF 1996;313:1095-6.

21 Lewin J, King M. Sexual medicine. BMF 1997;314:1432.

22 Chandler BJ, Brown S. How are patients' sexual and relationship difficulties dealt with by rehabilitation doctors? A survey of British Society of Rehabilitation Medicine members. Clinical Rehabilitation 1998;12:181-2.

23 Galasko D, Klauber MR, Hofstetter R, et al. The mini mental state examination in the early diagnosis of Alzeimer's disease. Arch Neurol 1990;47:49-52.

24 Goldberg D, Williams P. A users guide to the general health questionnaire. Berkshire: NFER-Nelson, 1988.

25 Barlow DH. Causes of sexual dysfunction. The role of anxiety and cognitive interference. Four Consult Clin Psychol 1986;54:104-48.

26 Mathew RJ, Weinman ML. Sexual dysfunctions in depression. Arch Sex Behav 1982;11:323-8.

27 Martin J, Meltzer H, Elliot D. The prevalence of disability amongst adults. OPCS surveys of disability in Britain, report 1. London: HMSO, 1988.

28 Rothwell PM, McDowell Z, Wong CK, et al. Doctors and patients don't agree: cross sectional study of patients' and doctors' perceptions and assessments of disability in multiple sclerosis. BMF 1997;314:1580-3.

29 Rust J, Bennun I, Crowe M, et al. The Golombok Rust inventory of marital state. Windsor: NFER-Nelson, 1988

30 Collier JL. The use of the GRIMS and the GRISS in the assessment and outcome of sexual problems: are questionnaires of more value than a clinical interview? Sexual and Marital Therapy 1989;4:11-16.

31 Rust J, Golombok S, Collier J. Marital problems and sexual dysfunction: how are they related? Br f Psychiaty 1988;152: 629-31

32 Rosenbaum $M$, Najenson $T$. Changes in life patterns and symptoms of low mood as reported by wives of severely brain injured soldiers. F Consult Clin Psychol 1976;44:8818.

33 Abrams KS. The impact on marriage of adult onset paraplegia. International Medical Society of Paraplegia 1981; 19:253-9.

34 Hartman C, MacIntosh B, Englehardt B. The neglected and forgotton sexual partner of the physically disabled. Social Work 1983;28:370-4

35 DeLoach C, Greer BG. Adjustment to severe physical disability. A metamorphosis. New York: McGraw Hill, 1981.

36 Anderson BJ, Wolf RM. Chronic physical illness and sexual behaviour: psychological issues. $\mathcal{f}$ Consult Clin Psychol 1986;54:168-75.

37 Webster L. Working with couples in a diabetic clinic: the role of the therapist in a medical setting. Special issue: couple therapy. Sexual and Marital Therapy 1992;7:189-96.

38 Zimmer D. Does marital therapy enhance the effectiveness of treatment for sexual dysfunction? Fournal of Sexual and Marital Therapy 1987;13:193-209. 